\title{
Studies on the mass action effect of glucose in NIDDM and IDDM: evidence for glucose resistance
}

\author{
S. D el Prato ${ }^{1}$, M. M atsuda ${ }^{2}$, D.C. Simonson ${ }^{3}$, L. C. G roop ${ }^{4}$, P. Sheehan ${ }^{2}$, F. Leonetti ${ }^{5}$, R .C. B onadonna ${ }^{6}$, \\ R.A. D eFronzo 2 \\ ${ }^{1}$ Cattedra di Malattie del Metabolismo, University of Padova, Italy \\ ${ }^{2}$ Division of Diabetes, Health Science Center at San Antonio, University of Texas, San Antonio, Texas, USA \\ ${ }^{3}$ Department of Diabetes and Metabolism, Brigham and Women Hospital, Boston, Massachussets, USA \\ ${ }^{4}$ Department of Endocrinology, University of Lund, Malmo, Sweden \\ ${ }^{5}$ Clinica Medica, University La Sapienza, Roma, Italy \\ ${ }^{6}$ Cattedra di Endocrinologia e Malattie del Metabolismo, University of Verona, Italy
}

Summary The ability of hyperglycaemia to enhance glucose uptake was evaluated in 9 non-insulin-dependent (NIDDM), 7 insulin-dependent (IDDM) diabetic subjects, and in 6 young and 9 older normal volunteers. Following overnight insulin-induced euglycaemia, a sequential three-step hyperglycaemic clamp $(+2.8+5.6$, and $+11.2 \mathrm{mmol} / \mathrm{l}$ above baseline $)$ was performed with somatostatin plus replacing doses of basal insulin and glucagon, $3-{ }^{3} \mathrm{H}$-glucose infusion and indirect calorimetry. In the control subjects as a whole, glucose disposal increased at each hyperglycaemic step $(13.1 \pm 0.6,15.7 \pm 0.7$, and $26.3 \pm$ $1.1 \mu \mathrm{mol} / \mathrm{kg} \cdot \mathrm{min})$. In NIDDM $(10.5 \pm 0.2,12.1 \pm 1.0$, and $17.5 \pm 1.1 \mu \mathrm{mol} / \mathrm{kg} \cdot \mathrm{min})$, and IDDM (11.2 \pm 0.8 , $12.9 \pm 1.0$, and $15.6 \pm 1.1 \mu \mathrm{mol} / \mathrm{kg} \cdot \mathrm{min})$ glucose disposal was lower during all three steps $(p<0.05-$ $0.005)$. Hepatic glucose production declined proportionally to plasma glucose concentration to a similar extent in all four groups of patients. In control subjects, hyperglycaemia stimulated glucose oxidation $(+4.4 \pm 0.7 \mu \mathrm{mol} / \mathrm{kg} \cdot \mathrm{min})$ only at +11.2 $\mathrm{mmol} / \mathrm{l}(\mathrm{p}<0.05)$, while non-oxidative glucose metabolism increased at each hyperglycaemic step $(+3.1 \pm 0.7 ; \quad+3.5 \pm 0.9, \quad$ and $+10.8 \pm 1.7 \mu \mathrm{mol} / \mathrm{kg}$. min; all $p<0.05)$. In diabetic patients, no increment in glucose oxidation was elicited even at the highest hyperglycaemic plateau $\quad(\mathrm{IDDM}=+0.5 \pm 1.5$; $\mathrm{NIDDM}=+0.2 \pm 0.6 \mu \mathrm{mol} / \mathrm{kg} \cdot \mathrm{min})$ and non-oxidative glucose metabolism was hampered (IDDM = $+1.8 \pm 1.5,+3.1 \pm 1.7$, and $+4.3 \pm 1.8 ; \quad$ NIDDM $=$ $+0.7 \pm 0.6, \quad 2.1 \pm 0.9$, and $+7.0 \pm 0.8 \mu \mathrm{mol} / \mathrm{kg} \cdot \mathrm{min}$; $p<0.05-0.005)$. Blood lactate concentration increased and plasma non-esterified fatty acid (NEFA) fell in control $(p<0.05)$ but not in diabetic subjects. The increments in blood lactate were correlated with the increase in non-oxidative glucose disposal and with the decrease in plasma NEFA. In conclusion: 1) the ability of hyperglycaemia to promote glucose disposal is impaired in NIDDM and IDDM;2) stimulation of glucose oxidation and non-oxidative glucose metabolism accounts for glucose disposal; 3) both pathways of glucose metabolism are impaired in diabetic patients; 4) impaired ability of hyperglycaemia to suppress plasma NEFA is present in these patients. These results suggest that glucose resistance, that is the ability of glucose itself to promote glucose utilization, is impaired in both IDDM and NIDDM patients. [Diabetologia (1997) 40: 687-697]

Keywords Hyperglycaemia, mass action effect, glucose-mediated glucose metabolism, glucose oxidation, non-oxidative glucose metabolism.
Received: 20 August 1996 and in revised form: 5 March 1997

Corresponding author: S. Del Prato, M. D., Cattedra di Malattie del Ricambio, Via Giustiniani, 2, I-35128 Padova, Italy A bbreviations: NIDDM, non-insulin-dependent diabetes mellitus; IDDM, insulin-dependent diabetes mellitus; NEFA, non-esterified fatty acids; $R_{a}$, rate of appearance; $R_{d}$, rate of disappearance; HGP, hepatic glucose production.
Tissue glucose uptake occurs via a facilitated transport system [1]. The major factors that regulate glucose uptake in vivo are the prevailing plasma glucose and insulin concentrations. Following glucose ingestion the plasma glucose concentration rises, insulin secretion is stimulated and the combination of hyperglycaemia and hyperinsulinaemia contributes to the increase in glucose utilization. Plasma glucose concentration influences glucose utilization by a mass 
Table 1. Summary of clinical data in young and older control, NIDDM and IDDM subjects

\begin{tabular}{llllllll}
\hline & Number & $\begin{array}{l}\text { male/ } \\
\text { female }\end{array}$ & $\begin{array}{l}\text { Age } \\
(\text { years })\end{array}$ & $\begin{array}{l}\text { BMI } \\
\left(\mathrm{kg} / \mathrm{m}^{2}\right)\end{array}$ & $\begin{array}{l}\text { Diabetes duration } \\
\text { (years) }\end{array}$ & $\begin{array}{l}\text { HbA }_{1 \mathrm{c}} \\
(\%)\end{array}$ & $\begin{array}{l}\text { Fasting plasma glucose } \\
(\mathrm{mmol} / \mathrm{l})\end{array}$ \\
\hline Young control subjects & 6 & $4 / 2$ & $25 \pm 3$ & $22.1 \pm 1.5$ & - & $5.4 \pm 0.2$ & $4.8 \pm 0.1$ \\
Older control subjects & 9 & $6 / 3$ & $59 \pm 2$ & $26.2 \pm 0.7$ & - & $5.7 \pm 0.2$ & $4.9 \pm 0.2$ \\
IDDM & 7 & $5 / 2$ & $34 \pm 3$ & $22.5 \pm 0.6$ & $13 \pm 4$ & $8.4 \pm 0.9^{\mathrm{a}}$ & $5.4 \pm 0.4$ \\
NIDDM & 9 & $7 / 2$ & $62 \pm 2$ & $27.0 \pm 0.9$ & $11 \pm 3$ & $8.2 \pm 0.4^{\mathrm{a}}$ & $5.7 \pm 0.2$ \\
\hline
\end{tabular}

Data are mean \pm SEM

${ }^{a} p<0.05$ vs respective control group

action effect which is independent of insulin [2]. Insulin stimulates glucose disposal by increasing the translocation and intrinsic activity of the GLUT4 transporter [3, 4], whereas hyperglycaemia promotes glucose uptake primarily via the GLUT1 transporter [5] although more recent findings suggest a stimulation/activation of GLUT4 as well [6].

Insulin resistance is a prominent feature of the diabetic state. Numerous studies, employing a variety of techniques, have demonstrated that insulin-mediated glucose uptake is markedly impaired in non-insulindependent-diabetic (NIDDM) patients [7]. A defect in insulin action also has been described in poorly controlled insulin-dependent diabetic (IDDM) subjects $[8,9]$. Although insulin resistance is a characteristic feature of both NIDDM and IDDM, little is known about the ability of hyperglycaemia per se to enhance glucose uptake in diabetes. This is an important question since it has been suggested that in normal man as much as half of the decline in plasma glucose concentration following glucose administration is due to the mass action effect of hyperglycaemia [10]. Soskin and Levine in 1937 were the first to study the relationship between the blood glucose level and glucose utilization in pancreatectomized diabetic dogs and suggested that hyperglycaemia provided a compensatory mechanism to maintain normal rates of tissue glucose uptake in the presence of insulin deficiency [11]. We, as well as others, have demonstrated that in both NIDDM and IDDM individuals hyperglycaemia serves a compensatory role to offset the insulin resistance and maintain a normal rate of insulin-mediated glucose disposal [7, 8, 12-15]. Despite the important role of hyperglycaemia in the maintenance of glucose homeostasis in diabetic individuals, few studies have examined the effect of hyperglycaemia on glucose utilization, and these have yielded conflicting results [16-19]. In part, these apparently discrepant results are due to differences in experimental design and to the failure to recognize the important role of basal insulinaemia in determining the intracellular metabolic partitioning of glucose when examining the mass action effect of glucose to stimulate its own uptake [20]. In the present study we have investigated the ability of hyperglycaemia to enhance glucose uptake while maintaining the plasma insulin concentration constant at the basal level in NIDDM, IDDM, and control subjects. Our data provide evidence that resistance to the mass action effect of glucose to stimulate its own uptake contributes to the impairment in glucose homeostasis in diabetes mellitus.

\section{Subjects and methods}

Subjects. The study population consisted of 7 IDDM and 9 NIDDM subjects (Table 1). They were compared to 6 young and 9 older subjects, respectively, who were of similar age and body weight. All subjects were of Caucasian descent. The duration of diabetes and degree of metabolic control were similar in the two diabetic groups (Table 1). All of the IDDM subjects typically had their onset of diabetes at a young age, had previously been admitted in diabetic ketoacidosis, and were insulin requiring (mean daily dose $=49 \pm 4$ IU/day). The NIDDM subjects typically had the onset of their disease after the age of 45 and were controlled with sulfonylurea agents $(n=7)$ or $\operatorname{diet}(n=2)$. The sulfonylurea was stopped 3 days prior to study in the 7 NIDDM subjects who were receiving oral agent treatment. All participants were consuming a weight-maintaining diet that contained at least $250 \mathrm{~g}$ of carbohydrate per day for 3 days before the study. Other than insulin, no subject took any medication for at least 2 weeks prior to study. Prior to their participation the purpose, nature, and risks of the study were explained to all subjects and their voluntary, informed, written consent was obtained. The experimental protocol was approved by the Human Investigation Committee of Yale University School of Medicine, and the Institutional Review Board of the UTHSC.

Experimental protocol. Diabetic subjects were admitted to the Clinical Research Center on the morning of the day prior to study. IDDM patients received their usual morning (08.00 hours) insulin dose (regular and/or intermediate acting insulin). Only regular insulin was injected with the dinner meal on the evening prior to study. At 20.00 hours an intravenous insulin infusion was begun via an antecubital vein in both the IDDM and NIDDM subjects and the insulin infusion rate $(0.1-0.2 \mathrm{mU} / \mathrm{kg} \cdot \mathrm{min})$ was adjusted on the basis of frequent plasma glucose measurements to achieve normoglycaemia $(5.0-5.6 \mathrm{mmol} / \mathrm{l})$. During the $4 \mathrm{~h}$ preceding initiation of the study the insulin infusion was maintained constant and stable euglycaemia was documented in all patients.

All studies were performed with the subject in the recumbent position starting at $08.00 \mathrm{~h}$ after a $10-12 \mathrm{~h}$ overnight fast. Prior to study, a teflon catheter was inserted retrogradely into a wrist vein in the hand controlateral to the antecubital catheter and kept patent with a slow infusion of isotonic saline solution. The hand was then inserted into a heated box $\left(70^{\circ} \mathrm{C}\right)$ to achieve arterialization of venous blood. In all subjects 
120 min before beginning the hyperglycaemic clamp studies a priming dose $(25 \mu \mathrm{Ci})$ of $3-{ }^{3} \mathrm{H}$-glucose was rapidly injected via the antecubital catheter and a constant infusion $(0.25 \mu \mathrm{Ci} /$ min) of tritiated glucose was begun and continued until the end of the study. Sixty minutes before beginning the hyperglycaemic clamp studies, continuous respiratory gas exchange measurements also were begun and continued throughout. After the $120 \mathrm{~min}$ equilibration period for tritiated glucose, all subjects underwent a three-step hyperglycaemic clamp study in which the plasma glucose concentration was acutely raised and maintained constant at $+2.8,+5.6$, and $+11.2 \mathrm{mmol} / \mathrm{l}$ above baseline. Each hyperglycaemic step lasted for $100 \mathrm{~min}$. Five minutes before starting the hyperglycaemic clamp studies in diabetic and control subjects, infusions of somatostatin $(400 \mu \mathrm{g} / \mathrm{h})$, insulin $(0.1-0.2 \mathrm{mU} / \mathrm{kg} \cdot \mathrm{min})$ and glucagon $(0.5$ $\mathrm{ng} / \mathrm{kg} \cdot \mathrm{min})$ were initiated via the antecubital catheter and kept constant throughout the entire study. The rate of insulin infusion in diabetic subjects was the same as that employed during the last $4 \mathrm{~h}$ of the overnight infusion to maintain euglycaemia $(0.14 \pm 0.02$ and $0.21 \pm 0.03 \mathrm{mU} / \mathrm{kg} \cdot \mathrm{min}$, respectively). Normal subjects received a constant infusion of insulin at the rate of $0.1 \mathrm{mU} / \mathrm{kg} \cdot \mathrm{min}$. Somatostatin (Serono, Italy), regular insulin (Lilly, Indianapolis, Ind., USA), and glucagon (Novo Industri $\mathrm{A} / \mathrm{S}$, Copenhagen, Denmark) were mixed in a $0.3 \%$ human albumin solution and infused at constant rate.

H yperglycaemic clamp study. The three-step hyperglycaemic clamp study was performed as previously described [21]. Briefly, a priming dose of glucose was infused in a logarithmically decreasing manner over $15 \mathrm{~min}$ in order to rapidly achieve the desired hyperglycaemic plateau. Subsequently, the plasma glucose concentration was held constant at the desired level by determination of the plasma glucose concentration every $5 \mathrm{~min}$ and appropriately adjusting a $20 \%$ glucose solution based on a negative feedback principle [22]. Each new plasma glucose plateau lasted $100 \mathrm{~min}$. During the basal period and throughout the hyperglycaemic clamp, plasma samples were drawn at 10-15 min intervals for determination of plasma hormone and substrate levels and every 5-10 min for tritiated glucose specific activity.

Respiratory exchange measurements. Starting $60 \mathrm{~min}$ before and continuing throughout the stepwise hyperglycaemic clamp studies, continuous indirect calorimetry was performed as previously described [23]. A transparent plastic ventilated hood was placed over the head of the subject and made airtight around the neck. A slight negative pressure was maintained in the hood to avoid loss of expired air. Ventilation was measured by means of a dry gas meter (American Meter Division, Singer Co., Philadelphia, Pa., USA). A constant fraction of the air flowing out of the hood was automatically collected for analysis. The oxygen content was continuously measured by electrochemical analysis (Model S-3A Oxygen Analyzer; Applied Electrochemistry Inc., Sunnyvale, Calif., USA) and carbon dioxide content by an infrared analyser (Model CD-3A Carbon Dioxide Analyzer; Applied Electrochemistry). Urine was collected throughout the basal period and again during the entire hyperglycaemic clamp study and the urinary nitrogen excretion during these periods was used to calculate protein oxidation [24].

A nalytical procedures. Plasma glucose concentration was determined in duplicate by the glucose-oxidase method on a Beckman Analyzer II (Beckman Instruments Inc., Fullerton, Calif., USA). Methods for the determination of plasma tritiated glucose specific activity, plasma immunoreactive insulin, glucagon, plasma non-esterified fatty acids (NEFA), and blood lactate have been described previously [25]. In IDDM subjects plasma-free insulin was determined after precipitation with polyethylene glycol [26]. Urinary nitrogen excretion was determined according to the method of Kjeldahl [27].

Calculations. In all studies a steady-state plateau of plasma tritiated glucose specific activity was achieved during the $30 \mathrm{~min}$ period prior to starting the hyperglycaemic clamp study. Hepatic glucose production (HGP) in the basal state was determined by dividing the $3-{ }^{3} \mathrm{H}$-glucose infusion rate (counts $/ \mathrm{min}$ ) by the steady-state plateau of $3-{ }^{3} \mathrm{H}$-glucose specific activity (counts/mg) which was achieved during the last $30 \mathrm{~min}$ of the pre-clamp period in all subjects. During the hyperglycaemic clamp studies a non-steady-state condition with respect to glucose specific activity exists and rates of glucose appearance $\left(\mathrm{R}_{\mathrm{a}}\right)$ and disappearance $\left(\mathrm{R}_{\mathrm{d}}\right)$ were calculated by Steele's equation [28] using a pool fraction value of 0.65 [29]. HGP was calculated by subtracting the exogenous glucose infusion rate from the rate of glucose appearance $\left(R_{a}\right)$ as determined by the isotopic tracer technique. Although errors in the calculation of kinetic parameters may be generated by changes in plasma $3-{ }^{3} \mathrm{H}$-glucose specific activities, their magnitude is likely to be trivial in this set of studies given the generally low rate of glucose metabolism and the constancy of plasma levels of glucose, insulin, and tritiated glucose radioactivity [30, 31].

Glucose oxidation rates were calculated from continuous calorimetric measurements [33] during the last $60 \mathrm{~min}$ of each hyperglycaemic step and are expressed in $\mu \mathrm{mol} / \mathrm{kg} \cdot \mathrm{min}$. Nonoxidative glucose disposal was calculated by subtracting the rate of glucose oxidation from the rate of total body glucose uptake. During each hyperglycaemic plateau total glucose metabolism was corrected for urinary glucose losses. For data presentation, the mean of the last $60 \mathrm{~min}$ for each hyperglycaemic step is presented.

\section{Statistical analysis}

All data are presented as mean \pm SEM. All statistical comparisons between groups were performed by analysis of variance. Changes from baseline within a group were determined by the paired t-test. In all comparisons diabetic subjects were compared to their appropriate age-matched group. There were no significant differences in any metabolic parameter or substrate or hormone concentration between the young and older control groups. Therefore, for the purpose of clarity of data presentation, old and young control subjects have been combined in the figures. The group data for the young and older control subjects are presented separately in the text.

\section{Results}

Plasma glucose and hormone concentrations (Fig. 1). Plasma glucose, insulin and glucagon concentrations in the basal state and during the three-step hyperglycaemic clamp studies are displayed in Figure 1. After the overnight insulin infusion, plasma glucose concentrations in NIDDM $(5.7 \pm 0.2 \mathrm{mmol} / \mathrm{l})$ and $\operatorname{IDDM}(5.4 \pm 0.4 \mathrm{mmol} / \mathrm{l})$ were slightly higher than in the older control $(4.9 \pm 0.2 \mathrm{mmol} / \mathrm{l})$ and young control $(4.8 \pm 0.1 \mathrm{mmol} / \mathrm{l})$ subjects, respectively. No difference in any metabolic parameter was observed between young and older subjects. Plasma glucose 


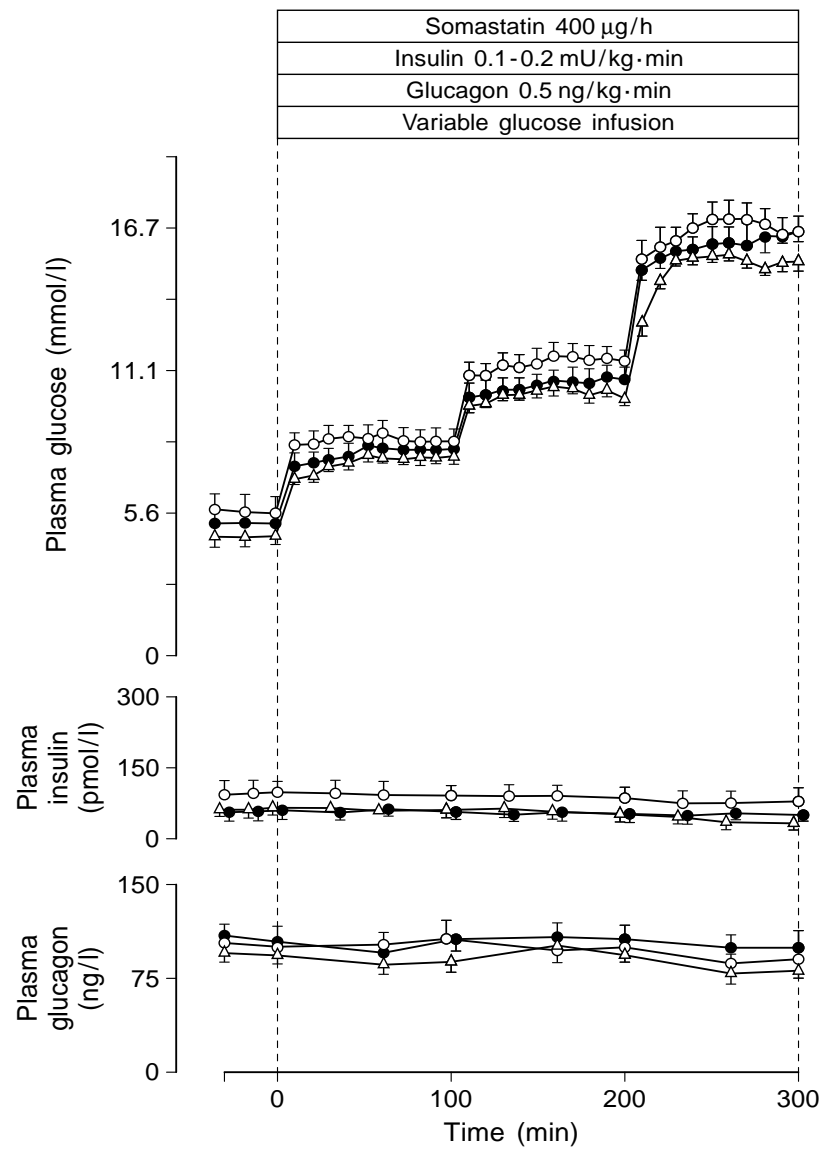

Fig. 1. Plasma glucose, insulin and glucagon concentrations (mean \pm SEM) before and during the three-step hyperglycaemic clamp studies in control $(\triangle), \operatorname{IDDM}(\mathbf{O})$, and NIDDM (○) subjects

Fig. 2. Time course of glucose infusion rates and plasma glucose specific activities during the three-step hyperglycaemic clamp studies. Panel A: young control subjects ( $\square$ ) and IDDM patients $(\square)$. Panel B: older control subjects $(\square)$ and NIDDM patients $(\bigcirc \square)$. Data are given as mean \pm SEM concentration was elevated by the same increment in normal subjects (by $3.2 \pm 0.1,5.8 \pm 0.1$, and $11.1 \pm$ $0.1 \mathrm{mmol} / \mathrm{l}$ in young control and $3.1 \pm 0.2,5.7 \pm 0.1$, and $11.2 \pm 0.2 \mathrm{mmol} / 1$ in older control subjects), in NIDDM subjects (by $2.9 \pm 0.1,5.9 \pm 0.1$, and $11.2 \pm$ $0.2 \mathrm{mmol} / \mathrm{l}$ ) and in IDDM subjects (by $2.8 \pm 0.1$, $5.7 \pm 0.2$, and $11.2 \pm 0.2 \mathrm{mmol} / \mathrm{l})$. During each hyperglycaemic clamp study the coefficient of variation in plasma glucose was less than $5 \%$. The fasting plasma insulin concentration was similar in young control $(84 \pm 6 \mathrm{pmol} / \mathrm{l})$, older control $(72 \pm 6 \mathrm{pmol} / \mathrm{l})$, and IDDM subjects $(78 \pm 12 \mathrm{pmol} / \mathrm{l})$. The fasting plasma insulin concentration $(126 \pm 18 \mathrm{pmol} / \mathrm{l})$ in NIDDM subjects was significantly elevated compared to the older controls $(p<0.001)$. In all four groups the arterialized plasma insulin concentration (young $=84 \pm$ $6 ;$ older $=66 \pm 6 ;$ IDDM $=72 \pm 6 ; \quad$ NIDDM $=102 \pm$ $12 \mathrm{pmol} / \mathrm{l})$ was held constant throughout the entire study despite progressively rising plasma glucose levels (Fig.1). The fasting plasma glucagon concentrations in the young control, older control, IDDM and NIDDM groups were $102 \pm 5,173 \pm 21,150 \pm 17$, and $125 \pm 12 \mathrm{ng} / \mathrm{l}$, respectively, and did not change significantly during the hyperglycaemic clamp studies $(102 \pm 9,186 \pm 24,135 \pm 7$, and $118 \pm 14 \mathrm{ng} / \mathrm{l}$, respectively) (Fig. 1).

Total glucose metabolism (Table 2 and Fig. 2 and 3). Glucose utilization was calculated by tracer techniques. The rates of exogenous glucose infusion and the time course of plasma glucose specific activity are illustrated in Figure 2. In the postabsorptive state, glucose utilization $\left(R_{d}\right)$ equals the rate of endogenous glucose appearance $\left(R_{a}\right)$. After the overnight insulin infusion no difference was found in basal glucose uptake between any of the four groups (Table 2). In normal young and older subjects the increase in plasma glucose concentration resulted in a progressive enhancement of total glucose metabolism. The

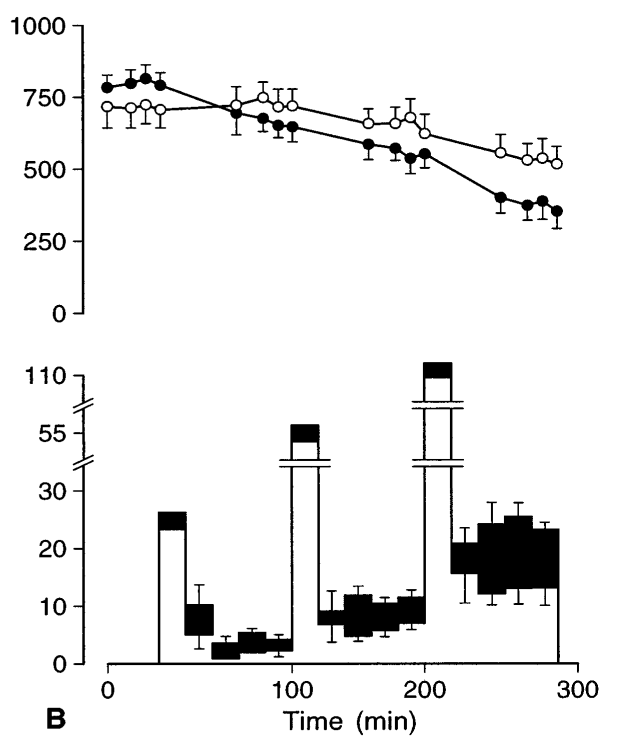


Table 2. Total body glucose uptake $(\mu \mathrm{mol} / \mathrm{kg} \cdot \mathrm{min})$ in the basal state and during the three step hyperglycaemic clamp studies

\begin{tabular}{lllll}
\hline & & & \multicolumn{3}{l}{ Hyperglycaemic clamp } \\
\cline { 3 - 5 } & Basal & $+2.8 \mu \mathrm{mol} / 1$ & $+5.6 \mu \mathrm{mol} / \mathrm{l}$ & $+11.2 \mu \mathrm{mol} / 1$ \\
\hline Young control subjects & $11.44 \pm 0.67$ & $12.94 \pm 0.78^{\mathrm{a}}$ & $16.11 \pm 0.83^{\mathrm{b}}$ & $25.83 \pm 2.06^{\mathrm{b}}$ \\
Older control subjects & $10.22 \pm 0.78$ & $12.94 \pm 2.77^{\mathrm{a}}$ & $14.89 \pm 0.83^{\mathrm{b}}$ & $26.00 \pm 3.06^{\mathrm{b}}$ \\
IDDM & $11.33 \pm 0.33$ & $11.22 \pm 0.78^{\mathrm{c}}$ & $12.89 \pm 1.06^{\mathrm{c}}$ & $15.61 \pm 1.11^{\mathrm{a}, \mathrm{c}}$ \\
NIDDM & $10.28 \pm 0.22$ & $10.50 \pm 0.22^{\mathrm{d}}$ & $12.06 \pm 1.22^{\mathrm{d}}$ & $17.33 \pm 1.39^{\mathrm{a}, \mathrm{d}}$ \\
\hline
\end{tabular}

Data are mean \pm SEM

${ }^{\mathrm{a}} p<0.05$ and $^{\mathrm{b}} p<0.005$ vs basal; ${ }^{\mathrm{c}} p<0.05$ vs young control subjects; ${ }^{\mathrm{d}} p<0.05$ vs older control subjects
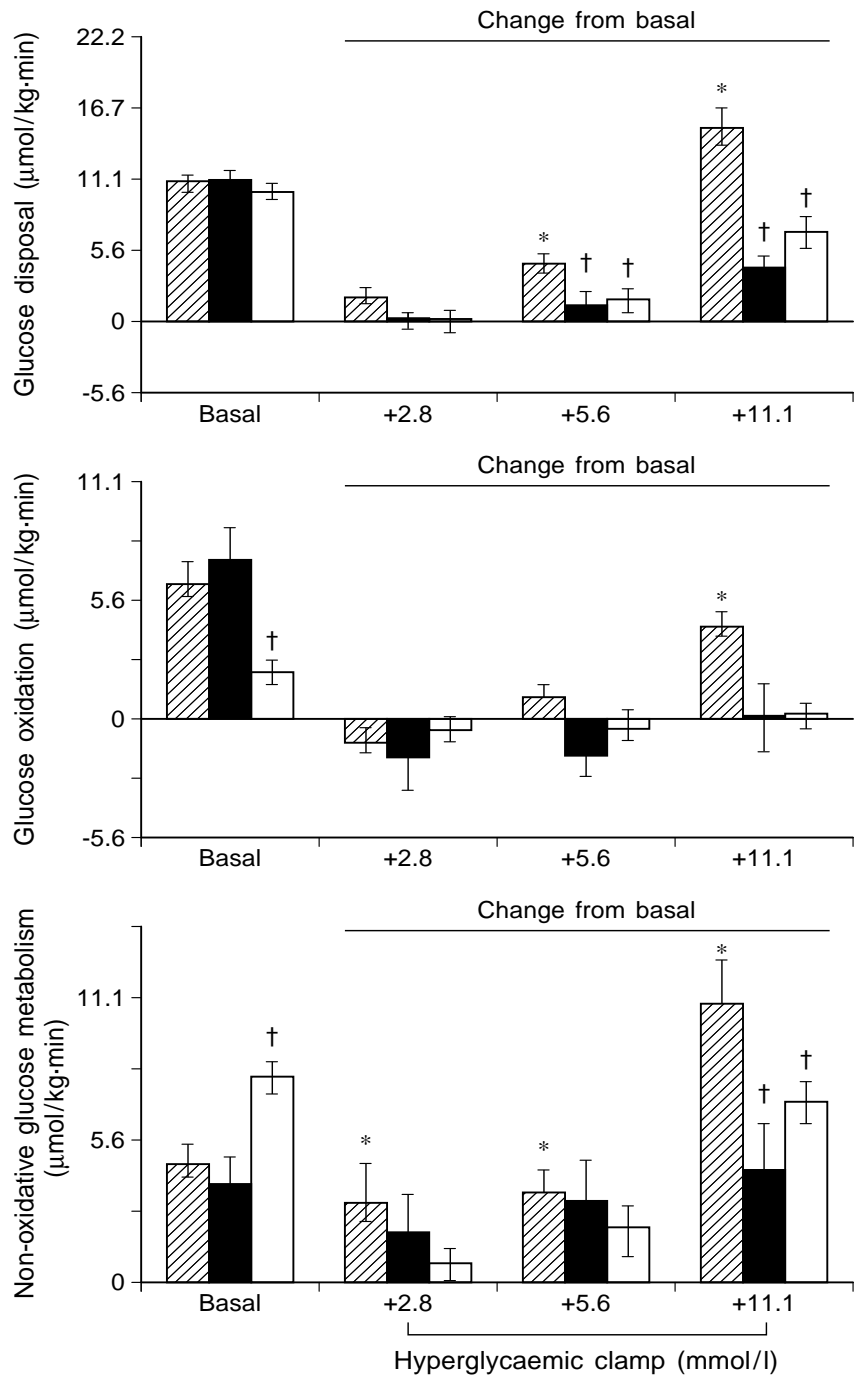

Fig. 3. Whole body glucose disposal (upper panel), oxidative (middle panel), and non-oxidative glucose disposal (lower panel) in the basal state and changes during the three-step hyperglycaemic clamp studies performed in control subjects (ख), IDDM ( $\square)$ and NIDDM $(\square)$ patients. Values represent the mean \pm SEM. $* p<0.05-0.005$ vs basal state; $\uparrow p<0.05-0.005$ vs control subjects

increment in glucose disposal $\left(\mathrm{R}_{\mathrm{d}}\right)$ in young subjects $(1.44 \pm 0.67, \quad 4.61 \pm 0.67$, and $14.4 \pm 2.22 \mu \mathrm{mol} / \mathrm{k}$. min) was similar to that observed in the older control subjects $\quad(2.67 \pm 0.78, \quad 4.67 \pm 0.61, \quad$ and $16.06 \pm$ $3.17 \mu \mathrm{mol} / \mathrm{kg} \cdot \mathrm{min})$ during the $+2.8+5.6$, and +
$11.2 \mathrm{mmol} / \mathrm{l}$ hyperglycaemic clamp studies, respectively. In contrast, the increment in total glucose metabolism in NIDDM $(0.22 \pm 0.72,1.83 \pm 1.00$, and $7.22 \pm 1.22 \mu \mathrm{mol} / \mathrm{kg} \cdot \mathrm{min})$ and in IDDM $(0.11 \pm 0.56$, $1.56 \pm 0.89$, and $4.33 \pm 0.94 \mu \mathrm{mol} / \mathrm{kg} \cdot \mathrm{min})$ subjects was significantly reduced compared to the corresponding age-matched control group during each of the three hyperglycaemic steps $(p<0.05-0.005)$.

H epatic glucose production (Table 3). After the overnight insulin infusion a normal HGP was achieved in NIDDM and IDDM subjects (Table 3). In normal young and older subjects, increasing the plasma glucose concentration by $+2.8,+5.6$, and $+11.2 \mathrm{mmol} / \mathrm{l}$ caused a progressive decline in HGP $(p<0.05-$ 0.005). The suppression of HGP in NIDDM and IDDM patients was similar to that observed in control individuals at each of the three hyperglycaemic steps. At the $+11.2 \mathrm{mmol} / \mathrm{l}$ hyperglycaemic plateau HGP was suppressed by over $80 \%$ in all four groups.

Oxidative and non-oxidative glucose metabolism (Fig. 3). In the postabsorptive state the rate of glucose oxidation was lower in NIDDM $(2.28 \pm 0.56 \mu \mathrm{mol} /$ $\mathrm{kg} \cdot \mathrm{min})$ compared to older control (6.39 \pm $1.06 \mu \mathrm{mol} / \mathrm{kg} \cdot \min ; \mathrm{p}<0.002)$ subjects, while no difference was apparent between IDDM and young control subjects $(7.61 \pm 1.11$ vs $6.40 \pm 0.89 \mu \mathrm{mol} / \mathrm{kg}$. min). In both young and older control subjects no stimulation of glucose oxidation was observed when the plasma glucose concentration was raised by +2.8 $(5.33 \pm 0.86$ and $5.67 \pm 0.94 \mu \mathrm{mol} / \mathrm{kg} \cdot \mathrm{min}$, respectively), and $+5.6 \mathrm{mmol} / \mathrm{l} \quad(7.67 \pm 1.12$ and $7.50 \pm$ $1.06 \mu \mathrm{mol} / \mathrm{kg} \cdot \mathrm{min}$, respectively). However, a significant elevation was appreciated during the +11.2 $\mathrm{mmol} / \mathrm{l}$ hyperglycaemic plateau $(10.72 \pm 1.78$ and $11.00 \pm 1.86$; both $p<0.05)$. On the contrary, in both NIDDM and IDDM groups hyperglycaemia failed to augment glucose oxidation above basal rates (IDDM $=5.88 \pm 1.56,6.06 \pm 1.06$, and $7.67 \pm 1.67$; $\mathrm{NIDDM}=1.83 \pm 0.51,00.94 \pm 0.56,2.5 \pm 0.25 \mu \mathrm{mol} /$ $\mathrm{kg} \cdot \min )$. The different response of diabetic and control individuals is better appreciated when the changes from baseline are plotted (Fig. 3).

Under basal conditions, non-oxidative glucose metabolism (Fig. 3) was not significantly different in young control and IDDM individuals $(5.00 \pm 1.17$ 
Table 3. Hepatic glucose production $(\mu \mathrm{mol} / \mathrm{kg} \cdot \mathrm{min})$ in the basal state and during the three-step hyperglycaemic clamp studies

\begin{tabular}{lllll}
\hline & & & \multicolumn{2}{l}{ Hyperglycaemic clamp } \\
\cline { 3 - 5 } & Basal & $+2.8 \mu \mathrm{mol} / \mathrm{l}$ & $+5.6 \mu \mathrm{mol} / 1$ & $+11.2 \mu \mathrm{mol} / 1$ \\
\hline Young control subjects & $11.44 \pm 0.67$ & $7.06 \pm 1.56$ & $6.22 \pm 1.28$ & $1.61 \pm 0.72$ \\
Older control subjects & $10.22 \pm 0.78$ & $9.67 \pm 1.06$ & $4.72 \pm 0.94$ & $1.22 \pm 0.78$ \\
IDDM & $11.33 \pm 0.33$ & $5.83 \pm 1.22$ & $4.94 \pm 1.50$ & $2.06 \pm 0.67$ \\
NIDDM & $10.28 \pm 0.22$ & $9.22 \pm 0.94$ & $5.39 \pm 0.83$ & $1.72 \pm 0.56$ \\
\hline
\end{tabular}

Data are mean \pm SEM

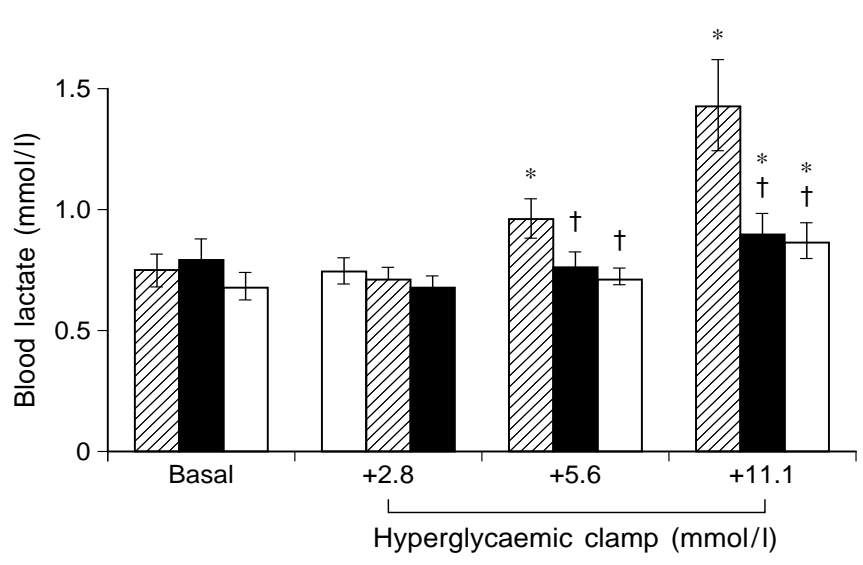

Fig. 4. Basal blood lactate concentrations and changes from baseline during a three-step hyperglycaemic clamp study in

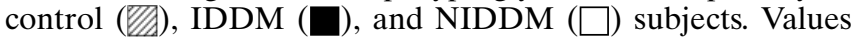
represent the mean \pm SEM. $* p<0.05-0.005$ vs basal state; $\uparrow \mathrm{p}<0.05-0.005$ vs control subjects

and $3.83 \pm 1.17 \mu \mathrm{mol} / \mathrm{kg} \cdot \mathrm{min})$, but it was higher in NIDDM patients $(8.00 \pm 0.56 \mu \mathrm{mol} / \mathrm{kg} \cdot \mathrm{min})$ when compared to older control subjects also (4.11 \pm $0.67 \mu \mathrm{mol} / \mathrm{kg} \cdot \mathrm{min} ; \mathrm{p}<0.002)$. During the three-step hyperglycaemic clamp, non-oxidative glucose disposal increased progressively both in the young (to $7.61 \pm 1.39, \quad 8.44 \pm 1.17$, and $15.11 \pm 1.50 \mu \mathrm{mol} / \mathrm{kg}$. min, each $p<0.05$ vs the previous step) and older control subjects (to $7.28 \pm 0.72,7.39 \pm 1.17$, and $15.00 \pm 2.56 \mu \mathrm{mol} / \mathrm{kg} \cdot \min$, each $\mathrm{p}<0.05 \mathrm{vs}$ the previous step). Non-oxidative glucose metabolism increased in the diabetic patients as well (IDDM $5.56 \pm 1.50,6.83 \pm 1.67$, and $8.00 \pm 1.78 ;$ NIDDM $8.67 \pm 0.67,10.05 \pm 1.00$, and $15.00 \pm 1.67 \mu \mathrm{mol} / \mathrm{kg}$. $\mathrm{min})$. The increments in non-oxidative glucose disposal during each of the three hyperglycaemic steps were reduced in both NIDDM and IDDM compared to their respective control groups $(p<0.05-0.005$; Fig. 2).

Blood lactate concentration (Fig.4). Basal blood lactate levels were similar in all four groups (young controls $\quad 0.68 \pm 0.06 \mathrm{mmol} / \mathrm{l} ; \quad$ older controls $0.80 \pm$ $0.09 \mathrm{mmol} / \mathrm{l} ; \quad \mathrm{NIDDM} \quad 0.78 \pm 0.09 \mathrm{mmol} / \mathrm{l} ; \quad$ IDDM $0.69 \pm 0.06 \mathrm{mmol} / \mathrm{l} ;$ Fig. 3 ). In young and older control individuals blood lactate concentrations increased progressively with each hyperglycaemic step $(p<$ 0.05-0.005; Fig.4). As was observed for total and non-oxidative glucose metabolism, the increment in blood lactate concentration was markedly and similarly blunted in NIDDM and IDDM patients and was significantly ( $p<0.05-0.005$; Fig. 4$)$ lower than in control subjects at each hyperglycaemic step. When the change in blood lactate concentration from basal was plotted against the change in non-oxidative glucose metabolism, a significant positive correlation was found in all four groups (Fig.5).

Plasma NE FA concentrations (Fig. 6) and lipid oxidation. There were no differences in the basal plasma NEFA levels in the four groups (young $=0.58 \pm 0.05$, older $=0.64 \pm 0.07, \quad$ IDDM $=0.65 \pm 0.08, \quad$ and $\mathrm{NIDDM}=0.67 \pm 0.08 \mathrm{mmol} / \mathrm{l}$; Fig. 6 ). In response to the stepwise increase in plasma glucose levels, the plasma NEFA concentrations fell progressively and similarly in both young $(0.44 \pm 0.06 \quad 0.37 \pm 0.05$, $0.30 \pm 0.05 \mathrm{mmol} / \mathrm{l}$; Fig. 6$)$ and older control subjects $(0.44 \pm 0.08, \quad 0.32 \pm 0.06, \quad 0.32 \pm 0.06 \mathrm{mmol} / \mathrm{l} ; \quad$ both $\mathrm{p}<0.05-0.005$ vs basal). A modest but blunted reduction in plasma NEFA was observed in IDDM, but not in NIDDM patients (Fig. 6). Basal lipid oxidation was similar in all groups (young $=3.70 \pm 0.33$; old $=$ $3.73 \pm 0.33 ; \quad$ IDDM $=3.33 \pm 0.39 ; \quad$ NIDDM $=3.62 \pm$ $0.33 \mu \mathrm{mol} / \mathrm{kg} \cdot \mathrm{min})$. Following stepwise increments in plasma glucose levels, lipid oxidation decreased in control subjects (young $=-0.47 \pm 0.18,-0.98 \pm 0.25$, $1.56 \pm 0.25 ;$ old $=-0.80 \pm 0.07,-1.16 \pm 0.15,-1.96 \pm$ $0.18 \mu \mathrm{mol} / \mathrm{kg} \cdot \mathrm{min}$ at each of the three hyperglycaemic steps; $p<0.05)$. Lipid oxidation decreased also in diabetic patients, although during the +11.2 $\mathrm{mmol} / \mathrm{l}$ hyperglycaemic clamp such a reduction was blunted $(p<0.05) \quad($ IDDM $=-0.40 \pm 0.07, \quad-0.80 \pm$ $0.18,-1.44 \pm 0.25 ; \quad \mathrm{NIDDM}=-0.54 \pm 0.18, \quad-0.76 \pm$ $0.11,-0.98 \pm 0.18 \mu \mathrm{mol} / \mathrm{kg} \cdot \mathrm{min})$.

A correlation was demonstrated between the decrement in plasma NEFA concentration and the increment in the rate of glucose-mediated glucose disposal in each group of individuals $(r=0.60,0.56,0.81$, and 0.52 for young, older, NIDDM, and IDDM subjects, respectively; $p<0.05-0.005)$. Furthermore, the decrement in plasma NEFA levels was correlated with the change in blood lactate concentration in all subjects as a whole $(r=0.71 ; p<0.001)$ as well as in each group $(r=0.55, r=0.72$, and $r=0.67$ for control, NIDDM, and IDDM subjects, respectively; $p<0.05-$ $0.01)$. 

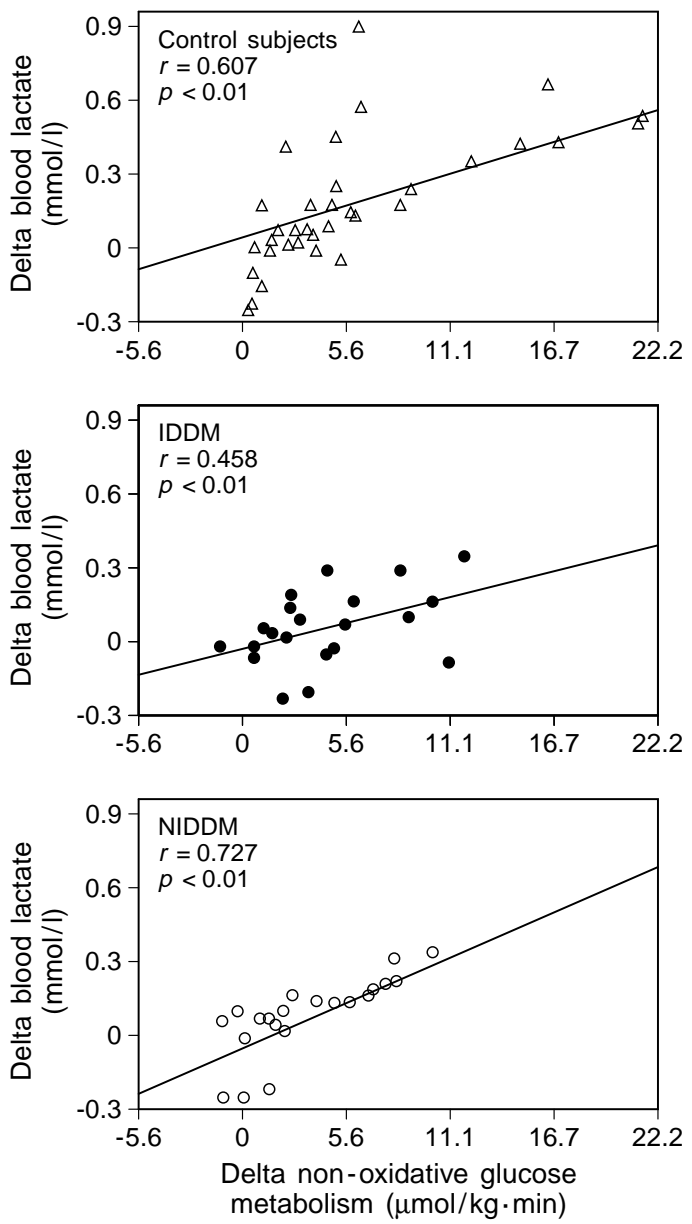

Fig. 5. Correlation between the increments above baseline in blood lactate concentration and non-oxidative glucose disposal in control and diabetic subjects

\section{Discussion}

In the diabetic condition, fasting hyperglycaemia provides a compensatory mechanism to maintain glucose metabolism relatively normal in the face of insulin deficiency and/or insulin resistance $[8,9,12,25,33]$. However, the mass action effect of glucose appears to be greater in normal than in diabetic subjects $[8$, $9,12,25,33$ ], suggesting the existence of a 'glucose resistance'. In the present study we examined directly the mass action effect of hyperglycaemia by fixing the plasma insulin at the basal level in normal and diabetic individuals. The maintenance of basal plasma insulin concentrations is of importance in evaluating the mass action effect of hyperglycaemia because acute hypoinsulinaemia: i) blocks the ability of hyperglycaemia to promote glucose uptake by the splanchnic area $(21,34]$; ii) causes a decline in the basal rate of glucose oxidation [34]; iii) alters the intracellular partitioning of glucose between the oxidative and non-oxidative pathways of glucose disposal in response to hyperglycaemia [20]. Our results demonstrate that the ability of hyperglycaemia to promote

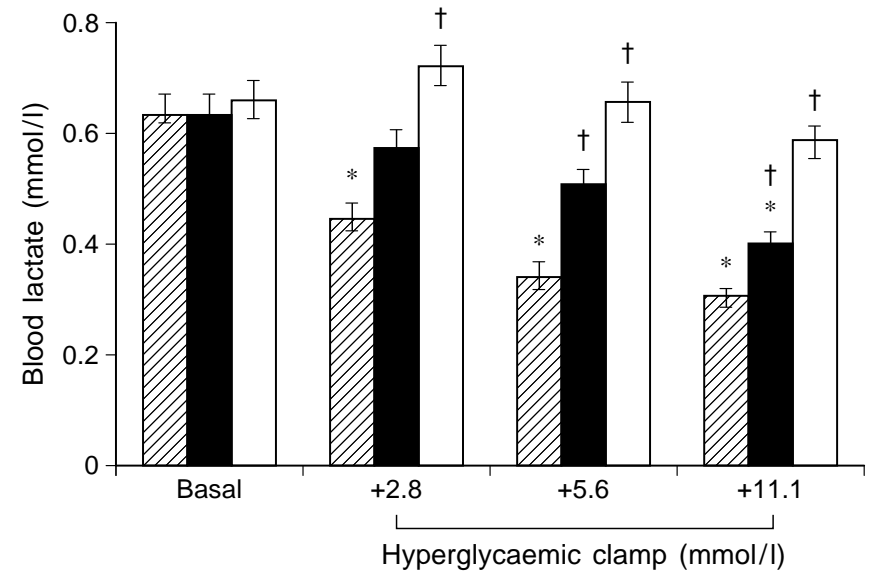

Fig. 6. Basal plasma NEFA concentrations and changes from baseline during a three-step hyperglycaemic clamp study in control (U), IDDM ( $\square$ ), and NIDDM $(\square)$ subjects. Values represent the mean \pm SEM. $* p<0.05-0.005$ vs basal state; $\uparrow p<0.05-0.005$ vs control subjects

whole body glucose uptake is impaired in NIDDM and IDDM subjects compared to control subjects. In healthy young and older subjects, as the plasma glucose concentration was increased, there was a progressive and highly significant increase in glucose utilization. In agreement with Meneilly et al. [35], the ability of hyperglycaemia to promote glucose uptake was similar in young and older control subjects, indicating in the latter the integrity of the cellular mechanisms responsible for the increase in glucose uptake in response to hyperglycaemia.

The diabetic condition is associated with a reduced ability of hyperglycaemia to enhance glucose uptake, i.e. glucose resistance. In both NIDDM and IDDM subjects, physiologic increments in the plasma glucose concentration failed to augment glucose disposal. Only when the plasma glucose concentration was raised to very high levels $(+11.2 \mathrm{mmol} / \mathrm{l})$ was a stimulation of glucose disposal observed. Since the plasma insulin concentration was maintained constant at the basal level in each subject, differences in plasma insulin levels between the control and diabetic individuals cannot explain the defect in glucose-mediated glucose uptake in the NIDDM and IDDM subjects. Nevertheless, we cannot rule out the possibility that the metabolic fate of glucose entering the cell might be affected by the different plasma insulin levels attained by hormone replacement. Basal plasma insulin concentration indeed does not affect the rate of glucose utilization induced by hyperglycaemia, but it regulates the distribution of glucose between oxidative and non-oxidative pathways [20].

The increase in glucose utilization following hyperglycaemia represents the sum of glucose uptake by all tissues of the body. In the postabsorptive state, when the plasma insulin concentration is at basal levels, the majority of glucose uptake occurs in 
insulin-insensitive tissues, mainly the brain and the splanchnic organs [36]. Glucose utilization by the central nervous system is saturated at plasma glucose concentrations over $3.3 \mathrm{mmol} / \mathrm{l}[37,38]$, whereas, in the presence of basal insulin levels, splanchnic glucose uptake augments in proportion to the degree of hyperglycaemia [2, 21, 39]. Thus, in the present study it is likely that the splanchnic tissues contributed to increase total body glucose uptake. Since, however, the splanchnic tissues only take up glucose in proportion to the prevailing plasma glucose concentration $[2,21,39]$ and since net brain glucose uptake is not enhanced by hyperglycaemia [37, 38], from a quantitative standpoint it is clear that peripheral tissues (muscle) were responsible for a significant proportion of glucose disposal. Consistent with this, Baron et al. [36] have shown that the majority of total body glucose uptake in response to insulinopenic hyperglycaemia occurs in muscle. In diabetic patients it is well established that peripheral tissues (muscle) represent the primary site of insulin resistance [23]. We now provide evidence that resistance to the mass action effect of hyperglycaemia (i.e. glucose resistance) occurs in muscle as well.

The most likely mechanism responsible for the glucose resistance in NIDDM and IDDM is an abnormality in the glucose transport system, possibly due to glucose toxicity [40]. Studies in both man [1, 41, 42] and animals [43, 44] have shown that sustained hyperglycaemia for as little as 6-24 h induces insulin resistance through a down regulation of the glucose transport system $[6,45]$ both at the level of insulin-independent and insulin-dependent tissues [46, 47].

The glucose taken up by peripheral tissues can be oxidized to carbon dioxide and water, stored as glycogen, or released as three carbon compounds. Basal glucose oxidation in the control groups averaged $6.4 \mu \mathrm{mol} / \mathrm{kg}$ min and was reduced by over $50 \%$ in NIDDM subjects, in agreement with previous observations [48, 49]. Hyperglycaemia stimulates glucose oxidation [50-52]. This was confirmed in the present study during the highest hyperglycaemic clamp step in normal subjects but not in IDDM or NIDDM patients. Whether the lack of activation of glucose oxidation in these patients represents a primary defect in the enzymatic regulation of pyruvate entry into the Kreb's cycle or it simply reflects the reduced rate of glucose utilization (phosphorylation) cannot be resolved by the present study. However, if we compare the results obtained during the $+11.2 \mathrm{mmol} / \mathrm{l}$ hyperglycaemic clamp in diabetic subjects with those of the $+5.6 \mathrm{mmol} / 1$ clamp in the control individuals (Fig. 3), that is at similar rates of glucose disposal, it can be appreciated that in no group was there a significant stimulation of glucose oxidation. It is also possible that the elevated plasma NEFA levels and higher lipid oxidation of diabetic subjects may contribute to the defect in glucose oxidation [53].
In contrast to glucose oxidation, non-oxidative glucose metabolism increased in response to maximal hyperglycaemic stimulation, although this was quantitatively reduced in both NIDDM and IDDM patients as compared to control subjects (Fig. 3). Therefore, it may be concluded that a more profound defect occurs in the ability of hyperglycaemia to stimulate glucose oxidation compared to non-oxidative glucose metabolism. Non-oxidative glucose metabolism includes glycogen formation and glucose conversion to lactate and lipids. Net lipid synthesis is unlikely in the absence of a respiratory quotient over 1. Hyperglycaemia, in the presence of basal plasma insulin levels, maintains but does not increase basal muscle glycogen levels [51]. The effect of hyperglycaemic euinsulinaemia on splanchnic (hepatic) glycogen synthesis is unknown but it cannot account for more than $2.8-5.6 \mu \mathrm{mol} / \mathrm{kg} \cdot$ min under the present experimental conditions [21]. Therefore, anaerobic glycolysis is likely to be stimulated by hyperglycaemia both in peripheral and splanchnic tissues. As the plasma glucose concentration progressively increased in normal subjects, there was a parallel increase in the plasma lactate level, which was closely correlated with the rise in non-oxidative glucose disposal (Fig.5). A similar correlation was found in IDDM and NIDDM patients, but for any given rate of nonoxidative glucose disposal the increments in blood lactate concentration were lower than in control subjects.

Fasting plasma NEFA concentrations were similar among groups despite higher plasma insulin levels in NIDDM patients, suggesting insulin resistance of adipose tissue. The existence of such a resistance has been previously demonstrated [25]. We now suggest that glucose resistance may involve the adipose tissue as well, since the reduction in plasma NEFA concentration observed with the progressive increase in plasma glucose levels was impaired in the diabetic subjects (Fig. 6). The ability of hyperglycaemia to inhibit lipid oxidation was altered as well. The persistence of higher plasma NEFA levels and higher lipid oxidation may contribute to the reduced rate of glucose utilization [53]. The positive correlation between the decrement in plasma NEFA concentration and the increment in glucose utilization is consistent with this hypothesis. Conversely, it is possible that the blunted rise in blood lactate concentration may contribute to impaired suppression of plasma NEFA levels, since lactate is known to inhibit lipolysis [54]. This possibility is supported by a relationship between the increments in blood lactate concentration and the suppression of plasma NEFA levels.

Our results may appear to contradict those of Baron et al. [16] and Alzaid et al. [55], who concluded that the mass action effect of glucose is normal in NIDDM subjects. However, there were several differences between their experimental protocols 
$[16,55]$ and our own. In Baron's study [16] fasting hyperglycaemia was clamped during suppression of plasma insulin levels by somatostatin infusion and glucose turnover measurements were obtained with tracer technique. Under conditions of acute insulinopenia no difference in the partitioning of glucose in control and diabetic subjects was found. However, the effect of induced insulinopenia rather than the ability of increasing concentration of plasma glucose concentration on glucose disposal was assessed. Alzaid et al. [55] determined insulin-mediated glucose uptake in NIDDM and non-diabetic subjects at glucose concentrations clamped at either $5 \mathrm{mmol} / \mathrm{l}$ (euglycaemia) or at plasma glucose levels varying to mimic glucose profile after food ingestion. In both experiments insulin was infused so as to simulate a 'non-diabetic' postprandial profile. Because the increment in glucose disposal from euglycemic to hyperglycaemic conditions was similar in NIDDM and non-diabetic subjects, they concluded that 'glucose effectiveness' was not impaired in NIDDM individuals. However, a major difference exists between their study and ours. In the former plasma insulin concentrations rose above basal while in the latter plasma insulin levels were held constant at baseline. It is possible that the concomitant presence of hyperinsulinaemia [55] was sufficient to overcome any defect in glucose-mediated glucose uptake.

Capaldo et al. [17] reported that insulinopenic hyperglycaemia stimulates forearm glucose uptake to a similar or even greater extent in NIDDM compared to control subjects. These investigators [17] infused glucose systemically to cause hyperglycaemia and then measured glucose uptake across forearm tissues. In contrast, we employed tritiated glucose to quantitate total body glucose disposal. As discussed earlier, one would expect the majority of the increase in glucose-mediated whole body glucose uptake in response to hyperglycaemia to occur in muscle. Therefore, it is difficult to reconcile their results [17] with those of our own. Because data on the rate of glucose infusion required to obtain comparable plasma glucose concentrations in control and NIDDM subjects were not presented by Capaldo et al. [17], it is not possible to determine whether whole body glucose disposal reflects forearm glucose uptake, and whether whole body glucose disposal was impaired in their diabetic patients. Furthermore, in our study the effect of hyperglycaemia on glucose disposal was evaluated under steady-state conditions. In contrast, in the study of Capaldo et al. [17] the plasma glucose concentration was continuously changing, as was the rate of forearm glucose uptake. As originally pointed out by Zierler [56], measurement of forearm glucose uptake under non-steady-state conditions may yield erroneous results. Finally, Capaldo et al. [17] did not replace basal insulin levels during somatostatin infusion. Thus, the ability of hyperglycaemia to enhance forearm glucose uptake was studied under hypoinsulinaemic conditions. This may have obliterated differences between control and diabetic subjects and explained the very low rates of forearm glucose uptake observed in both diabetic and control groups.

Finally, our results also confirm previous studies $[21,39,42,57]$ which demonstrated that hyperglycaemia exerts a suppressive effect on HGP in healthy young and older subjects. In NIDDM and IDDM subjects the overnight insulin infusion resulted in a normal postabsorptive HGP. When hyperglycaemia was induced in these diabetic subjects, HGP suppression was prompt and similar to that observed in normal subjects. However, we are cautious in suggesting a normal responsiveness of the liver to increasing plasma glucose levels under the present experimental conditions. No direct measurement of portal insulin was available. Moreover, plasma glucose specific activity was not kept constant throughout the hyperglycaemic clamp studies, so that changes over time may lead to underestimation of HGP [58]. Therefore, additional experiments are warranted before it can be concluded that hyperglycaemia causes a normal HGP suppression in IDDM and NIDDM subjects.

In conclusion, in addition to the well-established presence of insulin resistance in both NIDDM and IDDM patients $[7,8,20]$, our data now provide evidence that there is resistance to the stimulatory effect of hyperglycaemia on glucose disposal as well. Consistent with our findings, Welch et al. [18], using the minimal model technique, have also reported an impairment in glucose-mediated glucose uptake in NIDDM diabetic patients. A similar defect has been demonstrated by Arnfred et al. [19] in IDDM subjects using a protocol similar to that employed by us. The ageing process per se does not appear to be associated with glucose resistance, since glucose-mediated glucose uptake was similar in young and older healthy control subjects.

A cknowledgements. The authors thank the nurses of the Clinical Research Center for the excellent care of our patients, Syed Hasan for his technical assistance, and Lorrie Olivarri and Rosa Ramos-Echandi for their expert secretarial skills. This research was supported in part by NIH grants AG 00233 and AM 24092, and Clinical Research Center grant RR 00125.

\section{References}

1. Baldwin S, Leinhard G (1981) Glucose transport across plasma membranes: facilitated diffusion system. Trends Biochem Sci 6: 208-211

2. Cherrington AD, Williams P, Harris M (1978) Relationship between the plasma glucose level and glucose uptake in the conscious dog. Metabolism 27: 787-791

3. Cushman SW, Wardzala LJ (1980) Potential mechanism of insulin action on glucose transport in the isolated rat 
adipose cell. Apparent translocation of intracellular transport systems to the plasma membrane. J Biol Chem 255: 4758-4762

4. Klip A, P_quet MR (1990) Glucose transport and glucose transporters in muscle and their metabolic regulation. Diabetes Care:13: 228-240

5. Dimitrakoudis D, Ramlal T, Rastogi S, Vranic M, Klip A (1992) Glycaemia regulates the glucose transporter number in the plasma membrane of rat skeletal muscle. Biochem J 284: 341-348

6. Galante P, Mosthaf L, Kellerer M et al. (1995) Acute hyperglycaemia provides an insulin-independent inducer for GLUT4 translocation in $\mathrm{C}_{2} \mathrm{C}_{12}$ myotubes and rat skeletal muscle. Diabetes 44: 646-651

7. DeFronzo RA, Bonadonna RC, Ferrannini E (1992) Pathogenesis of NIDDM. A balanced overview. Diabetes Care/ Reviews 15: 318-366

8. DeFronzo RA, Hendler R, Simonson D (1982) Insulin resistance is a prominent feature of insulin-dependent diabetes. Diabetes 31: 795-801

9. Del Prato S, Nosadini R, Tiengo A et al. (1983) Insulin-mediated glucose disposal in type 1 diabetes: evidence for insulin resistance. J Clin Endocrinol Metab 57: 904-910

10. Ader M, Pacini G, Ysug YJ, Bergman RN (1985) Importance of glucose per se to intravenous glucose tolerance. Comparison of the minimal model prediction with direct measurements. Diabetes 34: 1092-1103

11. Soskin S, Levine R (1937) A relationship between the blood sugar and the rate of sugar utilization affecting theories of diabetes. Am J Physiol 120: 761-770

12. Del Prato S, Bonadonna RC, Bonora E, Gulli G, Solini A, Shank M, DeFronzo RA (1993) Characterization of cellular defects of insulin action in type 2 (non-insulin dependent) diabetes mellitus. J Clin Invest 91: 484-494

13. Franssila-Kallunki AI, Eriksson JG, Groop LC (1992) Timedependent effect of hyperglycaemia and hyperinsulinaemia on oxidative and non-oxidative glucose metabolism in patients with NIDDM. Acta Endocrinol 127: 100-108

14. Revers RR, Fink R, Griffin J, Olefsky JM, Kolterman OG (1984) Influence of hyperglycaemia on insulin's in vivo effects in type II diabetes. J Clin Invest 73: 664-672

15. Vaag A, Damsbo P, Hother-Nielsen O, Beck-Nielsen $\mathrm{H}$ (1992) Hyperglycaemia compensates for the defects in insulin-mediated glucose metabolism and in the activation of glycogen synthase in the skeletal muscle of patients with type 2 (non-insulin-dependent) diabetes mellitus. Diabetologia 35: $80-88$

16. Baron A, Kolterman G, Bell J, Mandarino L, Olefsky J (1985) Rates of noninsulin-mediated glucose uptake are elevated in type II diabetic subjects. J Clin Invest 76: 1782-1788

17. Capaldo B, Santoro D, Riccardi G, Perrotti N, Sacc_ L (1986) Direct evidence for a stimulatory effect of hyperglycaemia per se on peripheral glucose disposal in type II diabetes. J Clin Invest 77: 1285-1290

18. Welch S, Gebhan S, Bergman R, Phillips L (1990) Minimal model analysis of intravenous glucose tolerance test-derived insulin sensitivity in diabetic subjects. J Clin Endocrinol Metab 71: 1508-1549

19. Arnfred J, Schmitz O, Hother-Nielsen O et al. (1988) Marked impairment of the effect of hyperglycaemia on glucose uptake and glucose production in insulin-dependent diabetes. Diabet Med 5: 755-760

20. Del Prato S, Riccio A, Vigili de Kreutzenberg S, Dorella M, Tiengo A, DeFronzo RA (1995) Basal plasma insulin levels exert a qualitative but not quantitative effect on glucosemediated glucose uptake. Am J Physiol 268(Endocrinol Metab 31): E1089-E1095
21. DeFronzo RA, Ferrannini E, Hendler R, Felig P, Wahren J (1983) Regulation of splanchnic and peripheral glucose uptake by insulin and hyperglycaemia in man. Diabetes 32 : $35-45$

22. DeFronzo R, Tobin JD, Andres R (1979) Glucose clamp technique: a method for quantifying insulin secretion and resistance. Am J Physiol 273: E214-E223

23. DeFronzo RA, Jacot E, Jequier E, Maeder E, Wahren J, Felber JP (1981) The effect of insulin on the disposal of intravenous glucose. Results from indirect calorimetry and hepatic and femoral venous catheterization. Diabetes 30: 1000-1007

24. Simonson DC, DeFronzo RA (1990) Indirect calorimetry: methodological and interpretative problems. Am J Physiol 258:E399-E412

25. Groop LC, Bonadonna RC, Del Prato S et al. (1989) Glucose and free-fatty acid metabolism in non-insulin-dependent diabetes: evidence for multiple insulin resistance. $\mathbf{J}$ Clin Invest 84: 205-213, 1989

26. Nagakawa S, Nakayama T, Sasaki K et al. (1973) A simple method for the determination of serum free insulin levels in insulin-treated patients. Diabetes 22: 590-600

27. Hawk PD (1947) Kjeldal method. In: Practical Physiological Chemistry, 12th ed, Blakiston, Toronto, pp 814-822

28. Steele R (1959) Influence of glucose loading and of injected insulin on hepatic glucose output. Ann NY Acad Sci 82: $420-430$

29. Cowan JS, Hetenyi C (1971) Glucoregulatory responses in normal and diabetic dogs recorded by a new tracer method. Metabolism 20: 360-372

30. Ferrannini E, Smith J, Cobelli C, Toffolo G, Pilo A, De Fronzo RA (1985) Effects of insulin on the distribution and disposition of glucose in man. J Clin Invest 76: 357-364

31. Fisher SJ, Shi ZQ, Lickely HLA, Efendic S, Vranic M, Giacca A (1996) A moderate decline in specific activity does not lead to an underestimation of hepatic glucose production during a glucose clamp. Metabolism 45: 578593

32. Hother-Nielsen O, Staehr P (1993) Labeled glucose infusates in euglycemic clamp studies. Is precise matching of glucose specific activity important? Diabetes 45 [Suppl 2]:34A (Abstract)

33. DeFronzo RA, Simonson D, Ferrannini E (1982) Hepatic and peripheral insulin resistance: a common feature of type 2 (non-insulin-dependent) and type 1 (insulin-dependent) diabetes mellitus. Diabetologia 23: 313-319

34. Felber JP, Thiebaud D, Maeder E, Jequier E, Hendler R, DeFronzo RA (1983) Effect of somatostatin-induced insulinopenia on glucose oxidation in man. Diabetologia 25: 325-330

35. Meneilly GS, Elahi D, Minaker L, Sclter AL, Rowe JW (1989) Impairment of noninsulin-mediated glucose disposal in the elderly. J Clin Endocrinol Metab 68: 566-571

36. Baron AD, Brechtel G, Wallace P, Edelman SV (1988) Rates and tissue sites of non-insulin and insulin-mediated glucose uptake in humans. Am J Physiol 255 (Endocrinol Metab 18): E769-E774

37. Lund-Andersen H (1979) Transport of glucose from blood to brain. Physiol Rev 59: 305-352

38. Siesjo BK, Wieloch T (1988) Hypoglycemia, brain metabolism and brain damage. Diabetes Metab Rev 4: 113-144

39. Barrett EJ, Ferrannini E, Gusberg R, Bevilacqua S, DeFronzo RA (1985) Hepatic and extrahepatic splanchnic glucose metabolism in the postabsorptive and glucose fed dog. Metabolism 34: 410-420

40. Rossetti L, Giaccari A, DeFronzo RA (1990) Glucose toxicity. Diabetes Care Reviews 13: 610-630 
41. Vuorinen-Markkola H, Koivisto VA, Yki-Jarvinen H (1992) Mechanisms of hyperglycaemia-induced insulin resistance in whole body and skeletal muscle of type 1 diabetic patients. Diabetes 41: 571-580

42. Yki-Jarvinen H, Helve E, Koivisto VA (1987) Hyperglycaemia decreases glucose uptake in type 1 diabetes. Diabetes 36: 892-896

43. Kahn B, Shulman GI, DeFronzo RA, Cushman S, Rossetti L (1991) Normalization of blood glucose in diabetic rats with phlorizin treatment reverses insulin resistant glucose transport in adipose cells without restoring glucose transporter gene expression. J Clin Invest 87: 561-570

44. Lisato G, Cusin I, Tiengo A, Del Prato S, Jeanrenaud B (1992) The contribution of hyperglycaemia and hypoinsulinaemia to the insulin resistance of streptozotocin diabetic rats. Diabetologia 35: 310-315

45. Dimitrakoudis D, Vranic M, Klip A (1992) Effects of hyperglycaemia on glucose transporters of the muscle. J Am Soc Nephrol 3: 1078-1091

46. Gjedde A, Crone C (1981) Blood-brain glucose transfer: repression in chronic hyperglycaemia. Science 214 : 456-457

47. Sasson S, Edelson D, Cerasi E (1987) In vitro autoregulation of glucose utilization in rat soleus muscle. Diabetes 36: 1041-1046

48. Bogardus C, Lillioja S, Howard BV, Reaven G, Mott D (1984) Relationships between insulin secretion, insulin action, and fasting plasma glucose concentration in non-diabetic and noninsulin-dependent diabetic subjects. J Clin Invest 74: 1238-1246

49. Golay A, Felber JP, Jequier E, DeFronzo RA, Ferrannini F (1988) Metabolic basis of obesity and non-insulin dependent diabetes mellitus. Diabetes Metab Rev 4: 727-747

50. Kelley DE, Mandarino LJ (1990) Hyperglycaemia normalize insulin-stimulated skeletal muscle glucose oxidation and storage in noninsulin-dependent diabetes mellitus. J Clin Invest 86: 1999-2007

51. Vaag A, Hother-Nielsen O, Skutt P, Andersen P, Richter EA, Beck-Nielsen H (1992) Effect of acute hyperglycaemia on glucose metabolism in skeletal muscle in IDDM patients. Diabetes 41: 174-182

52. Yki-Järvinen H, Bogardus C, Howard B (1987) Hyperglycaemia stimulates carbohydrate oxidation in humans. Am J Physiol 253 (Endocrinol Metab 16): E376-E382

53. Randle PJ, Garland PB, Hales CN, Newsholme EA (1963) The glucose-fatty acid cycle: its role in insulin sensitivity and metabolic disturbances of diabetes mellitus. Lancet 1 : 785-789

54. Boyd AE III, Giamber SR, Mager M, Lebovitz HE (1974) Lactate inhibition of lipolysis in exercising man. Metabolism 23: 531-542

55. Alzaid AA, Dinneen S, Turk DJ, Caumo A, Cobelli C, Rizza RA (1994) Assessment of insulin action and glucose effectiveness in diabetic and nondiabetic humans. J Clin Invest 94: 2341-2348

56. Zierler KL (1961) Theory of the use of arteriovenous concentration differences for measuring metabolism in steady and non-steady states. J Clin Invest 40: 2111-2125

57. Saccà L, Hendler R, Sherwin RS (1978) Hyperglycaemia inhibits glucose production in man independent of changes in glucoregulatory hormones. J Clin Endocrinol Metab 47: 1160-1163

58. Finegood DT, Bergman RN, Vranic M (1988) Modeling error and apparent isotope discrimination confound estimation of endogenous glucose production during euglycaemic glucose clamps. Diabetes 37: 1025-1034 